\title{
STUDY OF PREVALENCE OF ANAEMIA AND IMPACT OF IRON SUPPLEMENTATION IN SCHOOL CHILDREN
}

\author{
Chinnatambi Narayanan Mohan Chandran'1, Burri Rambabu², Amujuri Krishna Prasad ${ }^{3}$, Duggirala Manikyamba ${ }^{4}$ Battina Manojna ${ }^{5}$ \\ ${ }^{1}$ Associate Professor, Department of Paediatrics, Rangaraya Medical College, Kakinada. \\ ${ }^{2}$ Assistant Professor, Department of Paediatrics, Rangaraya Medical College, Kakinada. \\ ${ }^{3}$ Associate Professor, Department of Paediatrics, Rangaraya Medical College, Kakinada. \\ ${ }^{4}$ Professor \& HOD, Department of Paediatrics, Rangaraya Medical College, Kakinada. \\ 5Junior Resident, Department of Paediatrics, Rangaraya Medical College, Kakinada.
}

\section{ABSTRACT}

Anaemia is the most widespread nutrition problem in the world and has predominance in developing countries like India, particularly in children and women. The magnitude of anaemia has been well-documented in pregnant women and infants, but there is scarce data on the prevailing occurrence of anaemia in school children. The current study was undertaken to know the point prevalence of anaemia and the comparative effectiveness of twice a week iron supplementation program to daily supplementation program in enhancing the hemoglobin levels in children aged 10-14 years with different grades of anemia in high schools in and around Kakinada, East Godavari district, Andhra Pradesh.

\section{METHODS}

A total of 400 children in the age group of 10-14 years were included in this study from both government and private schools by random sampling. After estimating the point prevalence of anaemia by Sahli's method all the children were given a single dose anti-helminthic and the children who were anaemic were further randomly divided into two subgroups A and B and allotted to either a daily or a twice weekly iron supplementation regimen respectively. The haemoglobin was again assessed after three months.

\section{RESULTS}

Point prevalence of anaemia among these children was 95.75\%. Prevalence of anaemia was significantly higher amongst girls (97.8\%) as compared to boys (93.9\%). Prevalence of anaemia was nearly equal in government (96\%) and private (95.5\%) schools. Mean improvement in $\mathrm{Hb} \%$ of $2.23 \mathrm{gm} \%$ and $1.98 \mathrm{gm} \%$ was seen in daily and weekly twice iron groups respectively with no significant difference between two groups. Reduction in prevalence of anemia was $86 \%$ in daily iron and $80 \%$ in weekly twice iron regimen group. Daily iron group experienced more side effects $(15.1 \%)$ when compared to weekly twice iron group (8.1\%).

\section{CONCLUSION}

This study shows that the point prevalence of anaemia in school children is high. Supervised iron and folic acid therapy twice a week is as effective as daily administration to lower the prevalence of anaemia with fewer side effects, less cost and better compliance.

\section{KEYWORDS}

Anaemia, Hemoglobin, School Children, Iron Supplementation.

HOW TO CITE THIS ARTICLE: Chandran CNM, Rambabu B, Prasad AK, et al. Study of prevalence of anaemia and impact of iron supplementation in school children. J. Evolution Med. Dent. Sci. 2016;5(16):758-762, DOI: 10.14260/jemds/2016/176

\section{INTRODUCTION}

Anaemia is a recognized public health problem throughout the world. ${ }^{1}$ An estimated 30 percent of the world's population is anaemic with the global prevalence of anaemia among 6-12 year old children to be 36 percent. $^{2}$ and 77 percent in developing regions respectively. ${ }^{3}$ Among the school age children (5-14 years) the prevalence has been estimated to be as high as $63 \%$ in South East Asian countries. In India an estimated 85 million children (74 percent) are anaemic. In earlier studies prevalence of anaemia among 5-14 year old urban and rural Indian children was found to be in the range of 66.7 to 77 percent. $^{4}$

Financial or Other, Competing Interest: None.

Submission 13-01-2016, Peer Review 05-02-2016,

Acceptance 13-02-2016, Published 24-02-2016.

Corresponding Author:

Dr. Battina Manojna,

Junior Resident,

Department of Paediatrics,

Rangaraya Medical College, Kakinada.

E-mail: bmanojna@yahoo.com

DOI: $10.14260 /$ jemds/2016/176
Recent studies on prevalence of anaemia have been on pre-schoolers only. ${ }^{5,6}$ Sant-Rayn Pasricha. ${ }^{7}$ conducted a study on determinants of anaemia among young children in rural India and found that poor nutrition and low socioeconomic status are the two important primary factors to be considered in anaemia. Baudouin A. Kokore et al. ${ }^{8}$ studied on the haematological status and anaemia prevalence among children aged 5 to 11 years in school canteens showed that $82.9 \%$ of children were having anaemia. There is a paucity of data on prevalence of anaemia among high school children in Andhra Pradesh. In view of high prevalence of anaemia, National Anaemia Prophylaxis Programme (NAPP) has been set up in all states of the country since 1970, but the benefits have not yet been appreciated in the target population because coverage of children under this programme is still poor.

The current study was undertaken to know the prevalence of anaemia and correlation with various variables like age, birth order and menarche. To know the comparative effectiveness of twice a week iron supplementation program to daily supplementation program in reducing the prevalence 
and severity of anemia and in enhancing the hemoglobin levels in children aged 10-14 years with different grades of anemia in high schools in and around Kakinada, East Godavari District.

\section{MATERIALS AND METHODS}

The study was conducted during May 2014 to April 2015 in the Department of Paediatrics, Government General Hospital, Kakinada, in nearby government and private high schools. After taking prior approval from the Institutional Ethical Committee (IEC) and permission from school authorities, children and parents, a total of 400 students studying $6^{\text {th }}$ to $9^{\text {th }}$ class between 10-14 years age group were included in the study. The number of school children between 10 to 14 years of age in nearby schools were 8044 for the year 2014-2015. A total of $5 \%$ of the children were included in the study, i.e. 402 (Rounded to 400). Every $5^{\text {th }}$ child was selected for the study by systemic random sampling. The process went on till we got the required sample size of 400 . The Children who met inclusion criteria (Studying 6th to 9th class and willing to participate in study) and exclusion criteria (Non-nutritional causes of anaemia like hemolytic anaemia, bone marrow hypoplasia, bleeding and coagulation disorders) were enrolled in the study and subjected to $\mathrm{Hb} \%$ estimation by Sahli's method. After estimating the point prevalence of anaemia, children who were not anemic and whose parents did not give consent to take IFA tablets were discarded from the study and rest of the children belonging to each grade of anaemia were further divided into two subgroups A and B by simple random sampling using table of random numbers and allotted to either a daily or a twice weekly supplementation regimen. Baseline assessment was done for nutritional status and majority of children were moderately nourished according to WHO standard charts. Haemoglobin estimation, both before and after intervention, was done by the same Lab Technician who was blinded regarding distribution of children in different Intervention groups.

The subjects were de-wormed with a single dose of $400 \mathrm{mg}$ Albendazole one week prior to supplementation. The supplement used consisted of $100 \mathrm{mg}$ of elemental iron (Ferrous sulphate) and $0.5 \mathrm{mg}$ of folic acid and was obtained from government of AP. Supplementation was carried out under the strict supervision of respective class teachers and the supplement was administered at around 4.00 p.m., three hours after lunch and three hours before dinner. Subjects were given the supplement either daily or on every
Wednesday and Saturday depending on the regimen they belonged to in prophylactic doses and children identified as severely anaemic were given IFA in therapeutic doses under close supervision. The period of supplementation was 3 months, (i.e. 12 weeks). A record of the attendance, morbidity and side effects experienced by each subject was maintained.

Blood samples were obtained from each subject by pin prick method at the beginning of the study and at the end of twelve weeks. Hemoglobin was estimated and group means and standard deviations were calculated and Chi square test was carried out to test the significance of difference between means of values of different groups as well as within the group at the end of supplementation.

\section{RESULTS}

Out of 400 students, 213 (53.3\%) were boys and 187(46.7\%) were girls. Government school children were 200 (50\%) and private school children were 200 (50\%). Anaemia is graded as per WHO definition of anaemia. ${ }^{9}$ The present study showed that the point prevalence of anaemia among children in the age between 10 to 14 years was $95.75 \%(383 / 400)$. It was observed that out of 400 children, 17 children $(4.25 \%)$ were normal, 43 children (10.5\%) were mildly anaemic, 309 children $(77.25 \%)$ were moderately anaemic and 31 children (7.75\%) were severely anaemic. Among the government school children, 96\% were anaemic and among private school children $95.5 \%$ were anaemic. Graph-1 shows prevalence of various grades of anaemia in study population.

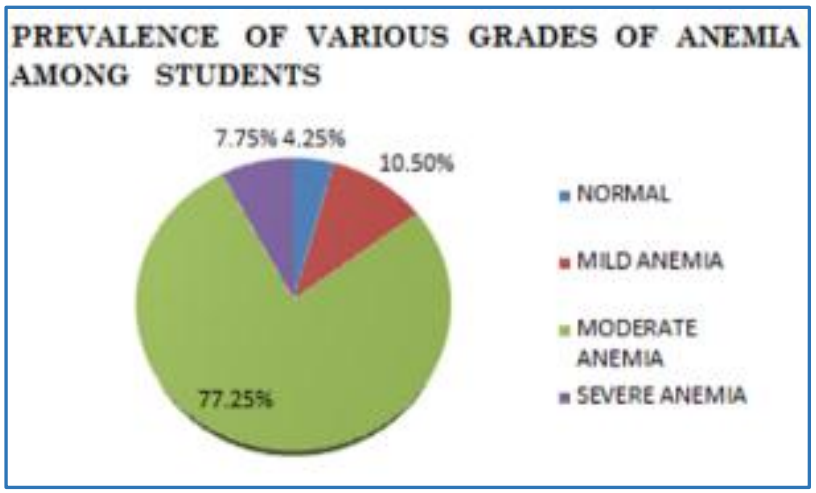

Graph 1

\begin{tabular}{|c|c|c|c|c|c|}
\hline $\begin{array}{c}\text { GRADE } \\
\text { OF ANAEMIA }\end{array}$ & BOYS & GIRLS & $\begin{array}{c}\text { GOVT. } \\
\text { SCHOOLS }\end{array}$ & PVT. SCHOOLS & TOTAL \\
\hline NORMAL & $13(6.1 \%)$ & $4(2.2 \%)$ & $8(4 \%)$ & $9(4.5 \%)$ & $17(4.25 \%)$ \\
\hline MILD ANAEMIA & $24(11.2 \%)$ & $19(10.2 \%)$ & $27(13.5 \%)$ & $16(8 \%)$ & $43(10.75 \%)$ \\
\hline MODERATE ANAEMIA & $166(78 \%)$ & $143(76.4 \%)$ & $151(75.5 \%)$ & $158(79 \%)$ & $309(77.25 \%)$ \\
\hline $\begin{array}{c}\text { SEVERE } \\
\text { ANAEMIA }\end{array}$ & $10(4.7 \%)$ & $21(11.2 \%)$ & $14(7 \%)$ & $17(8.5 \%)$ & $31(7.75 \%)$ \\
\hline PREVALENCE Table 1: Comparison of prevalence of various grades of anaemia in Boys versus \\
Girls and Government schools versus Private schools
\end{tabular}

Table 1 shows that majority of children (77.25\%) were moderately anaemic. The prevalence of anaemia was high among girls (97.8\%) when compared to boys (93.9\%) with a significant $p$ value of 0.04 .
This study also shows that among severely anaemic children, girls $(11.2 \%)$ were more when compared to boys $(4.75 \%)$ with a significant $p$ value of 0.003 . 
Prevalence of anaemia was almost equal in government (96\%) and private (95.5\%) schools with no significant difference between them.

\begin{tabular}{|c|c|c|c|c|}
\hline FACTORS & $\begin{array}{c}\text { ANAEMIC } \\
\text { N (\%) }\end{array}$ & $\begin{array}{c}\text { NORMAL } \\
\text { N (\%) }\end{array}$ & TOTAL & P VALUE \\
\hline $\begin{array}{c}\text { BIRTH } \\
\text { ORDER }\end{array}$ & & & & \\
\hline 1 \& 2 & $310(94.8)$ & $17(5.2)$ & 327 & 0.046 \\
\hline $3 \&$ above & $73(100)$ & 0 & 73 & \\
\hline AGE GROUP & & & & \\
\hline $10-12$ YRS & $179(94.2)$ & $11(5.8)$ & 190 & 0.101 \\
\hline $12-14$ YRS & $204(97.2)$ & $6(2.8)$ & 210 & \\
\hline MENARCHE & & & & \\
\hline Attained & $106(100)$ & 0 & $106(56.7)$ & 0.02 \\
\hline Not attained & $77(95)$ & $4(5)$ & $81(43.3)$ & \\
\hline TOTAL & $383(95.75)$ & $17(4.25)$ & $\mathbf{4 0 0}$ & \\
\hline \multicolumn{5}{|c|}{ Table 2: Association of various factors with anaemia } \\
\hline \multicolumn{7}{|l}{}
\end{tabular}

Table 2 shows association of various factors with anaemia. This study shows that prevalence of anaemia was high in children with birth order of 3 and above when compared to lower birth order showing that high birth order was significantly associated with anaemia with a $p$ value of 0.046. Prevalence of anaemia was high in children between 12-14 years when compared with younger children between $10-12$ years with a $p$ value of 0.101 , which is not statistically significant. Among girls prevalence of anaemia was high among them who attained menarche with a $\mathrm{p}$ value of 0.02 , which shows that attainment of menarche was significantly associated with anaemia among girls.

Effect of weekly twice versus daily iron supplementation in improving anaemic status of school children were documented in detail in Table 3 and 4 .

\begin{tabular}{|c|c|c|c|c|}
\hline \multirow{2}{*}{ GROUPS } & $\begin{array}{c}\text { BEFORE } \\
\text { INTERVENTI } \\
\text { ON } \\
\text { MEAN Hb\% }\end{array}$ & $\begin{array}{c}\text { AFTER } \\
\text { INTERVENTION } \\
\text { MEAN Hb\% }\end{array}$ & $\begin{array}{c}\text { MEAN } \\
\text { RISE } \\
\text { OF } \\
\text { Hb\% }\end{array}$ & $\begin{array}{c}\text { p } \\
\text { VALUE }\end{array}$ \\
\hline $\begin{array}{c}\text { DAILY } \\
\text { IRON }\end{array}$ & $8.96 \mathrm{gm}$ & $11.19 \mathrm{gm}$ & $\begin{array}{c}2.23 \mathrm{~g} \\
\mathrm{~m}\end{array}$ & \multirow{2}{*}{0.24} \\
\cline { 1 - 4 } $\begin{array}{c}\text { WEEKLY } \\
\text { TWICE } \\
\text { IRON }\end{array}$ & $8.85 \mathrm{gm}$ & $10.83 \mathrm{gm}$ & $\begin{array}{c}1.98 \mathrm{~g} \\
\mathrm{~m}\end{array}$ & \\
\cline { 1 - 2 } Table 3: Comparison of mean Hb level before and after \\
intervention among daily IFA and weekly twice IFA \\
supplementation
\end{tabular}

Table 3 and Graph 2 shows that daily and weekly twice iron supplementation were almost equally effective in improving $\mathrm{Hb}$ levels with a $\mathrm{p}$ value of 0.24 , which shows no significant difference between the two groups.

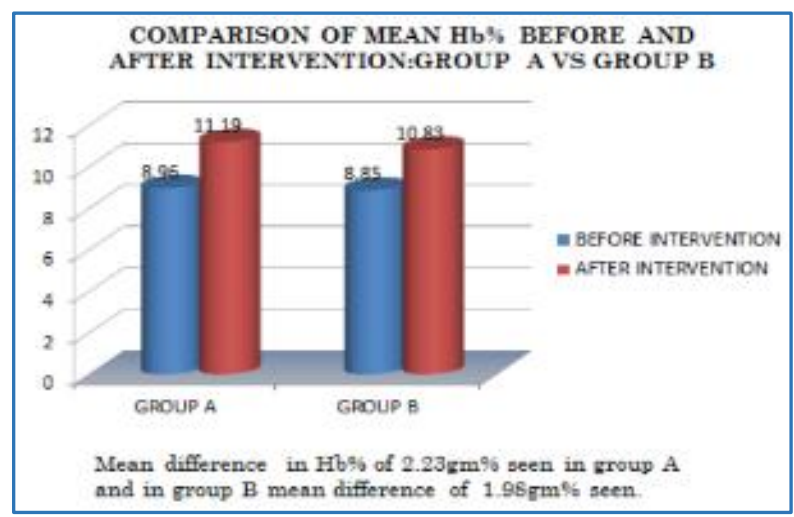

Graph 2

\begin{tabular}{|c|c|c|c|c|}
\hline \multirow{2}{*}{$\begin{array}{c}\text { Hemoglobin } \\
\text { Level }\end{array}$} & $\begin{array}{c}\text { Before } \\
\text { Intervention } \\
\text { N (\%) }\end{array}$ & \multicolumn{2}{|c|}{$\begin{array}{c}\text { After } \\
\text { Intervention } \\
\text { N (\%) }\end{array}$} & \multirow{2}{*}{$\begin{array}{c}\text { P } \\
\text { value }\end{array}$} \\
\cline { 3 - 4 } & GROUP A & GROUP B & \\
\hline Normal & $17(4.25 \%)$ & $\begin{array}{c}159 \\
(86 \%)\end{array}$ & $\begin{array}{c}148 \\
(80 \%)\end{array}$ & \multirow{2}{*}{0.12} \\
\cline { 1 - 4 } ANAEMIC & $\begin{array}{c}383 \\
(95.75 \%)\end{array}$ & $26(14 \%)$ & $37(20 \%)$ & \\
\cline { 1 - 4 } TOTAL & $\mathbf{4 0 0}$ & $\mathbf{1 8 5}$ & $\mathbf{1 8 5}$ & \\
\hline \multicolumn{3}{|c|}{ Table 4: Prevalence of Anaemia before \& after intervention } \\
\hline
\end{tabular}

Table 4 shows that prevalence of anaemia got reduced from $95.75 \%$ before intervention to $14 \%$ in daily iron group and $20 \%$ in weekly twice iron supplementation group with no significant difference between two groups.

\begin{tabular}{|c|c|c|c|c|c|c|}
\hline 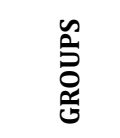 & 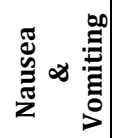 & 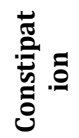 & 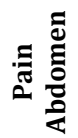 & 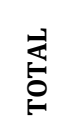 & $\delta^{0}$ & $\begin{array}{l}\stackrel{0}{\Xi} \\
\frac{\pi}{\pi} \\
\text { D. }\end{array}$ \\
\hline $\begin{array}{c}\text { GROUP } \\
\text { A }\end{array}$ & 12 & 10 & 6 & 28 & $15 . \%$ & \multirow{3}{*}{0.03} \\
\hline GROUP B & 8 & 5 & 2 & 15 & $8.1 \%$ & \\
\hline TOTAL & 20 & 15 & 8 & 43 & $11.6 \%$ & \\
\hline
\end{tabular}

Table 5 shows that $11.6 \%$ of children had side effects to iron therapy of which nausea and vomiting was most common side effect. Side effects were more in daily iron group $(15.1 \%)$ when compared to weekly twice iron group (8.1\%) with a significant difference between two groups with $\mathrm{p}$ value of 0.03 .

\section{DISCUSSION}

In the present study, $383(95.75 \%)$ children out of 400 were having anaemia and 17 (4.25\%) were normal. This indicates that anaemia is still a major public health problem. High proportion of children $(77.25 \%)$ were in moderate grade anaemia. In a similar study done by Sabale et al.10 in 461 children belonging to adolescent age group of 9-19 years from urban school children of Mumbai stated that 53.2\% of children suffer from anaemia. In a Study done by Amarnath et al. ${ }^{11}$ in 540 adolescent children of Visakhapatnam district documented that prevalence of anaemia was $95.5 \%$, which is almost similar to the present study.

Point prevalence of anaemia in girls (97.8\%) was significantly high when compared to boys $(93.9 \%)$ and more number of girls $(11.2 \%)$ were in severe grade of anaemia when compared to boys (4.7\%). This implies that both adolescent females as well as males should be targeted for control of anaemia because of additional requirement for growth and development during puberty and girls are more anaemic than boys in adolescent age, which could be because of hormonal changes and blood loss which occur after the onset of menarche which cause a further increase in iron requirements in them.

In the present study government school children who are expected to be undernourished, coming from low income group families and private school children who are expected to be well nourished, coming from high income group families were having equally high prevalence of anaemia with $96 \%$ and $95.5 \%$ in government and private schools respectively. 
It is evident from the present study that a significant proportion of apparently healthy children belonging to the high income group families suffer from overt anaemia and may have latent iron deficiency even if not anaemic. The possible reason for this could be the poor bio-availability of iron in the Indian diets.

The rising trend of consuming snacks and junk foods which supply empty calories is also responsible for so called 'Healthy,' but anaemic children from high income group families. ${ }^{12}$ This trend is also spreading in children from low income group families.

Present study showed that point prevalence of anaemia was $100 \%$ in girls who attained menarche and $95 \%$ in girls who did not attain menarche. Mean $\mathrm{Hb} \%$ was found to be $9.26 \mathrm{gm} \%$ in girls who did not attain menarche against mean $\mathrm{Hb} \%$ of $8.14 \mathrm{gm} \%$ in girls who attained menarche, which showed that anaemia was significantly associated with attainment of menarche in girls. The additional nutritional requirements for growth and development during puberty and extra losses during menstruation might cause a higher prevalence of anaemia in those who attained menarche. This finding suggests that dietary factors superimposed on physical growth spurt of adolescence and attaining menarche are playing a role in causation of anaemia.

The prevalence of anaemia was found to be increasing with increasing birth order with prevalence of $94.8 \%$ in children with birth order of 1 and 2 and 100\% in children with birth order of 3 and above. Anaemia is comparatively less in birth order one or two than birth order 3-4 due to dilution of household resources and mother's attention, as the birth order in the family increases. The present study showed that there is significant increase in risk of anaemia in children with higher birth order.

In the present study after intervention there was mean rise in $\mathrm{Hb}$ of $2.23 \mathrm{gm} \%$ in daily iron supplemented group and $1.98 \mathrm{gm} \%$ in weekly twice iron supplemented group. Supplementation with iron either daily or weekly twice brought about a significant increase in the hemoglobin levels. At the end of 3 months of supplementation, the hemoglobin status of weekly twice supplemented subjects is as good as daily supplemented subjects and there is no significant difference between the increases brought about by both in this study.

After intervention $86 \%$ of children from daily iron group and $80 \%$ of children from intermittent iron group got recovered from anaemia. At the end of the study overall prevalence of anaemia came down to $17 \%$ of which $13.2 \%$ of children were in mild grade of anaemia, 3.8\% were in moderate grade of anaemia and no child in severe grade of anaemia.

In the present study $15.1 \%$ of children in daily iron supplementation group and $8.1 \%$ children in intermittent supplementation group suffered unpleasant effects to iron with a $p$ value of 0.03 , which shows statistically significant difference between the two groups. One of the problems of iron supplementation is that it causes unpleasant gastrointestinal side effects like epigastric pain, nausea, vomiting, diarrhea, etc. This could be one of the reasons why many subjects discontinue the intake of the supplement.

Weekly twice supplementation seems to have a definite advantage over daily supplementation in this aspect.
This could probably be due to the avoidance of iron overload in the stomach of the subjects due to intermittent supplementation. ${ }^{13}$ there is, however, some consensus in that daily supplementation would be the fastest way to treat ID/IDA. There is some evidence that intermittent supplementation might also work. ${ }^{14}$

The present study shows that supervised administration of weekly twice supplementation of iron to anemic subjects is found to be as advantageous as daily supplementation as far as raising the hemoglobin levels were concerned. It has an edge over the traditional supplementation method with regards to occurrence of unpleasant side effects, which could perhaps lead to better compliance among subjects. Recent studies have indicated that iron supplements given weekly once or twice can be as effective as daily supplements, costs less, are better accepted and may have fewer side effects. ${ }^{15}$ Therefore, even if the absolute increase in haematological indexes in compliant individuals was slightly higher with daily supplementation, the positive effects in public health terms at the population level may be larger with less frequent supplementation. A less frequent schedule would mean less cost and better compliance and may have positive effects on programs.

\section{CONCLUSION}

The present study shows that the high prevalence of mild and moderate anaemia demands due emphasis, so as to bring down the total prevalence of anaemia in school children. They should be screened periodically and appropriate measures should be taken. There is a need for counselling parents to prevent their children from consuming junk foods, which is becoming a trend in nuclear families. Weekly twice supervised therapy is a good alternative to daily iron and folic acid administration. Weekly therapy appears to be equally effective yet causes fewer adverse effects, improves compliance and reduces the cost of supplementation. Weekly twice supplementation through school-based programs lowers the prevalence of anaemia in areas with high prevalence of the disease. It is recommended that further research to be done to document the efficacy and effectiveness of such intermittent IFA supplements. Larger, multicentric double blinded randomised control trials are required to confirm these results.

\section{REFERENCES}

1. Kishore J. National Health Programs of India. 9th edition. New Delhi: Century Publications; 2011:176.

2. DeMaeyer EM, Dallman P, Gurney JM, et al. Preventing and controlling iron deficiency anaemia through primary health care. Geneva: World Health Organization; 1989, p. 8-9.

3. Stoltzfus RJ, Chwaya HM, Tielsch JM, et al. Epidemiology of iron deficiency anaemia in Zanzibari school children: the importance of hookworms. Am J Clin Nutr 1997;65:153-9.

4. Verma M, Chhatwal J, Kaur G. Prevalence of anaemia among urban school children of Punjab. Indian Pediatr 1998;35:1181-6.

5. Sidhu S, Kumari K, Uppal M. Prevalence of anaemia in schedule cast preschool children of Punjab. Indian J Med Sci 2002;56:218-21. 
6. Kapoor D, Agarwal KN, Sharma S, et al. Iron status of children aged 9-36 months in an urban slum Integrated Child Development Services project in Delhi. Indian Pediatr 2002;39:136-44.

7. Pasricha SR, Black J, Muthayya S, et al. Determinants of anaemia among young children in rural India. American Academy of Paediatrics, 2010;126(1):140-149.

8. Kokore BA, Bleyere MN, Kouakou LK, et al. Haematological status and anaemia prevalence among children aged 5 to 11 years in school canteens in Abidjan. Middle-East Journal of Scientific Research, 2013;14(4):461-470.

9. WHO. Haemoglobin concentrations for the diagnosis of anaemia and assessment of severity. Vitamin and Mineral Nutrition Information System. Geneva, World Health Organization, 2011 (WHO/NMH/NHD/MNM/11.1) (http://www.who.int/vmnis/indicators/haemoglobin. pdf)

10. Sabale RV, Kowli SS, Chowdary PH. Prevalence of anaemia and its determinants in urban school-going children of Mumbai. Int J Med Public Health 2013;3:325-9.
11. Amarnath M, Rao N Lakshmana. Rural and urban variations in prevalence of anaemia among adolescent girls in Visakhapatnam District, Andhra Pradesh. Indian Journal of Public Health Research and Development, 2013;4(2):17-21.

12. Sudhagandhi B, Sundaresan S, Ebenezer W, et al. Prevalence of anaemia in the school children of Kattankulathur, Tamil Nadu, India. Int J Nutr Pharmacol Neurol Dis 2011;1:184-8.

13. Cook JD, Reddy MB. Efficacy of daily compared with weekly iron supplementation. Am J Clin Nutr 1995; 62:117-20.

14. Mora JO. Iron supplementation: overcoming technical and practical barriers. J Nutr 2002;132(4):853S-855S.

15. Schultink W, Gross R, Gliwitzki M, et al. Effect of daily vs twice weekly iron supplementation in Indonesian preschool children with low iron stores. Am J Clin Nutr 1995;61:111-15. 